\title{
Exploratory Analysis of the Total Variation of Electrons in the Ionosphere before Telluric Events Greater than M7.0 in the World during 2015-2016
}

\author{
Alva Mantari Alicia ${ }^{1}$, Zarate Segura Guillermo Wenceslao ${ }^{2}$, Sotomayor Beltran Carlos ${ }^{3}$ \\ Brian Meneses-Claudio ${ }^{4}$, Roman-Gonzalez Avid ${ }^{5}$ \\ Image Processing Research Laboratory (INTI-Lab), Universidad de Ciencias y Humanidades, Lima, Perú
}

\begin{abstract}
This exploratory observational study analyzes the variation of the total amount of vertical electrons (vTEC) in the ionosphere, 17 days before telluric events with grades greater than M7.0 between 2015 and 2016. Thirty telluric events have been analyzed with these characteristics. The data was obtained from 55 satellites and 300 GPS receivers that were downloaded from the Center for Orbit Determination in Europe (CODE). The variations are considered significant only if it is outside the "normal" ranges considered after the statistical analysis performed. The data was downloaded by a program developed in our laboratory. The downloaded data was processed and maps of variations of vTEC generated with a periodicity of 2 hours. The analysis area was considered to be a circular one with a radius of $1000 \mathrm{~km}$ centered on the epicenter of each earthquake. Variation of vTEC was found during $2015-2016$ in $100 \%$ of the earthquakes in the range from day 1 to day 17 days before the event, over the circular area of $1000 \mathrm{~km}$ radius centered on the epicenter of the earthquake. Of these in $96.55 \%$ there are positive variations and a negative one exist in $68.97 \%$ of the events. If we observe in the range from day 3 to 17 before the event, a variation was recorded in $100 \%$ of the cases, and from day 8 to day 17 before the event in $93.10 \%$ of the cases, it is important to emphasize that while the evidence in a period before the event is more likely to find evidence to develop early warning tool for earthquake prevention. This study explores the variation of vTEC as precursor events to each earthquake during 2015-2016; it is a preliminary analysis that shows us the feasibility of analyzing this information as a preamble for an exhaustive association study later. The final objective is to calculate the risk of telluric events which would benefit the population worldwide.
\end{abstract}

Keywords-Total number of electrons; ionosphere; earthquakes; prevention; risk

\section{INTRODUCTION}

Research related to the prevention of earthquakes is increasing in the last decades, due to the destruction and deaths they generate, this makes it imperative to look for methods that will help us predict them effectively. Earthquakes are movements of the earth's crust, which are a consequence of the sudden release of energy, due to the movement of tectonic plates [1]. The earthquakes are cataloged by different methods, depth or the energy that releases the movement. One of these scales is that of Richter, which quantifies the energy released by seismic movement. These exist in a range of dimensions from micro tremors of less than M2.0 to maximum values of more than M10.0 [2][3], although there is no reliable report of having reached M10.0, it is presumed that in the prehistoric era was reached these measures, the largest recorded earthquake on this scale is M9.5, in Chile on May $22^{\text {nd }}, 1960$. The greater intensity, greater destruction and damage to hundreds or thousands of kilometers, for example those in Sichuan (May $12^{\text {th }}, 2008$, M7.9), Samoa (September $29^{\text {th }}, 2009$, M8.1) and Haiti (January $12^{\text {th }}, 2010$, M7.0) were responsible for approximately 380,000 deaths and millions of victims [4]. We can notice that the earthquake greater than $M 7.0$ is the most dangerous, which there is an occurrence record of up to 18 per year [5] approximately. Our study has focused on earthquakes with these characteristics. Seismic grades greater than M7.0, considered the most devastating.

The study of the ionosphere has been of interest among different research groups due to its association with the prediction of telluric events [6]. The ionosphere is the area of the ionized atmosphere at a height greater than $70-80 \mathrm{~km}$, in which free electrons and ions form plasma, all data are taken at $450 \mathrm{~km}$ of distance in the ionosphere. Solar radiation is generated by the ionization of the area, which depends on solar activity, location and time of observation [7].

The use of this method analyzes the electron concentration of the ionosphere as an alternative of prediction $[8,9]$. It is the Total Quantity of Electrons (TEC) that is analyzed in its relation with the telluric movements. The TEC is defined based on the electronic density and the length of the path traveled by the solar emission. For our present study, we use the vertical number of electrons (vTEC), which is the projection of the TEC on a vertical path calculated as shown in Fig. 1.

To consider that an anomaly can be considered as an ancestor of an earthquake, we must fulfill 4 important requirements: (1) To be related to the deformation or the tectonic mechanism before earthquakes. (2) Be observed in 2 or more events. (3) Possess an amplitude in relation to the distance of the earthquake. (4) Define a risk area. Whose size must be respect to the studied area of the earthquake [10].

The global Ionosphere Maps (GIM) used in our research to analyze the association between the variation of the vTEC and seismic events greater than M7.0 during the years 2015-2016, were generated by the CODE, which receives data from the satellites and it provides vTEC information in the ionosphere, from a combined analysis of the values received from 55 satellites and 300 GPS receivers [11]. 


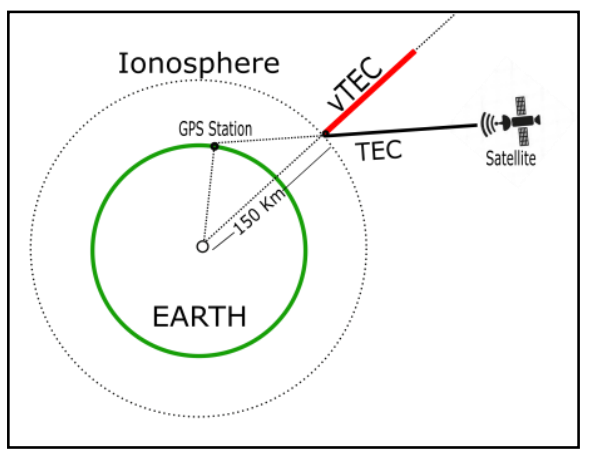

Fig. 1. Representation of Oblique TEC (sTEC) and Vertical TEC (vTEC).

\section{POPULATION}

\section{A. Sample}

The events that we are going to study for the association are those manifested during the 2015-2016 year. There were 30 seismic events greater than M7.0 degrees worldwide. These have been extracted from the database of IRIS Earthquake Browser [12], these have been geolocated on the map of the world using Qgis, as shown in Fig. 2.

These events have been placed in a Table I where it shows the place of the event, the latitude and longitude of the event, the grade of magnitude, and date, all data are shown in Table I.

Circular neighborhoods of $1000 \mathrm{~km}$ radius have been generated for each of the events [6], where the variation of vTEC will be analyzed during a predefined period of time of 17 days before the event. We can visualize the neighborhoods for the set of analysis events in the following Fig. 3.

The data of the vTEC variations have been generated for each hour and day of the event; from the data obtained by the code, the mean and the standard deviation of the vTEC variation are calculated from the data by a range of 8 days before and then, the significant variation which is considered over the ranges considered normal after the aforementioned statistic. So, we have maps for the analysis for each day of an event in 2015-2016, there are 17 days before the event and 4 days later, although we will only analyze the data of 17 days previously. The map of vTEC variations in the ionosphere is analyzed in rectangular areas of 2.5 latitude, and 5 longitude. The amount of data handled in this study can be seen in the following Table II.

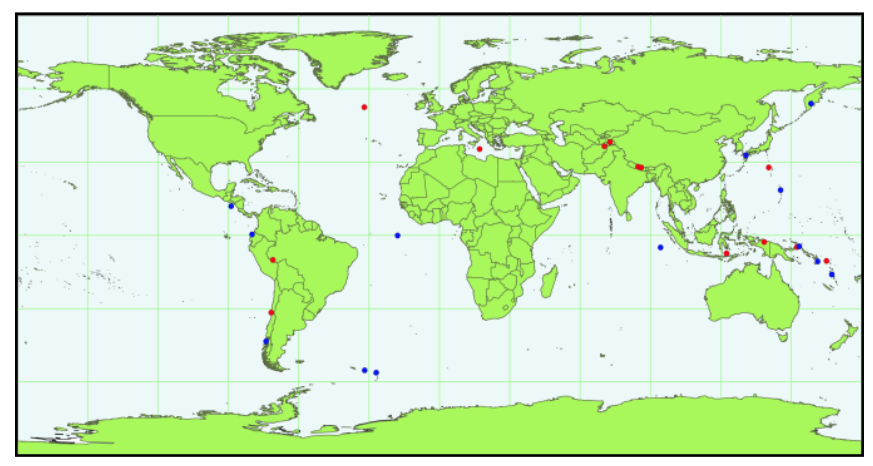

Fig. 2. Representation of the 30 Seismic Events Greater than M7.0, Worldwide. Red 2015. Blue 2016.
TABLE I. ABLE OF SEISMIC EVENTS OF 2015-2016 WITH INTENSITIES GREATER THAN M7.0

\begin{tabular}{|c|c|c|c|c|}
\hline \multicolumn{5}{|c|}{ Seismic events 2015-2016 } \\
\hline Place & Latitude & Longitude & Grade & Date \\
\hline $\begin{array}{l}\text { Dorsal Meso- } \\
\text { Atlantic North }\end{array}$ & 52.51 & -32.02 & 7.1 & $13 / 02 / 2015$ \\
\hline Indonesia & -7.36 & 122.49 & 7.0 & $27 / 02 / 2015$ \\
\hline $\begin{array}{l}\text { Papua Nueva } \\
\text { Guinea }\end{array}$ & -4.78 & 152.58 & 7.5 & $29 / 03 / 2015$ \\
\hline Nepal & 28.13 & 84.72 & 7.8 & $25 / 04 / 2015$ \\
\hline Japan & 27.83 & 140.49 & 7.8 & $30 / 05 / 2015$ \\
\hline Nepal & 27.80 & 86.13 & 7.3 & $12 / 05 / 2015$ \\
\hline $\begin{array}{l}\text { Dorsal Meso- } \\
\text { Atlantic South }\end{array}$ & 35.36 & 17.16 & 7.3 & $17 / 06 / 2015$ \\
\hline Solomon Islands & -10.46 & 165.1 & 7.0 & $18 / 07 / 2015$ \\
\hline Indonesia & -2.71 & 138.54 & 7.0 & $28 / 07 / 2015$ \\
\hline Chile & -31.64 & -71.74 & 8.4 & $16 / 09 / 2015$ \\
\hline Afghanistan & 36.52 & 70.37 & 7.5 & $26 / 10 / 2015$ \\
\hline Vanuatu & -14.86 & 167.3 & 7.1 & $21 / 10 / 2015$ \\
\hline Peru & -10.06 & -71.02 & 7.7 & $24 / 11 / 2015$ \\
\hline Pakistan & 38.21 & 72.78 & 7.2 & $07 / 12 / 2015$ \\
\hline Russia & 54.01 & 158.51 & 7.2 & $30 / 01 / 2016$ \\
\hline Indonesia & -4.95 & 94.33 & 7.8 & $02 / 03 / 2016$ \\
\hline Japan & 32.79 & 130.75 & 7 & $15 / 04 / 2016$ \\
\hline Ecuador & 0.38 & -79.92 & 7.8 & $16 / 04 / 2016$ \\
\hline Vanuatu & -16.04 & 167.38 & 7 & $28 / 04 / 2016$ \\
\hline Visokoy Island & -56.24 & -26.94 & 7.2 & $28 / 05 / 2016$ \\
\hline $\begin{array}{l}\text { Northern Mariana } \\
\text { Islands }\end{array}$ & 18.54 & 145.54 & 7.7 & $29 / 07 / 2016$ \\
\hline New Caledonia & -22.48 & 173.11 & 7.2 & $12 / 08 / 2016$ \\
\hline Argentina & -55.28 & -31.87 & 7.1 & $19 / 08 / 2016$ \\
\hline $\begin{array}{l}\text { Santa Elena, } \\
\text { Ascencion and } \\
\text { Tristan de Acuña }\end{array}$ & -0.05 & -17.83 & 7.1 & $29 / 08 / 2016$ \\
\hline New Zealand & -37.36 & 179.15 & 7 & $01 / 09 / 2016$ \\
\hline New Zealand & -42.72 & 173.06 & 7.8 & $13 / 11 / 2016$ \\
\hline El Salvador & 11.96 & -88.84 & 7.2 & $24 / 11 / 2016$ \\
\hline Solomon Islands & -10.68 & 161.33 & 7.8 & $09 / 12 / 2016$ \\
\hline Papua New Guinea & -4.5 & 153.52 & 8 & $17 / 12 / 2016$ \\
\hline Chile & -43.41 & -73.94 & 7.6 & $25 / 12 / 2016$ \\
\hline Russia & 54.01 & 158.51 & 7.2 & $30 / 01 / 2016$ \\
\hline
\end{tabular}

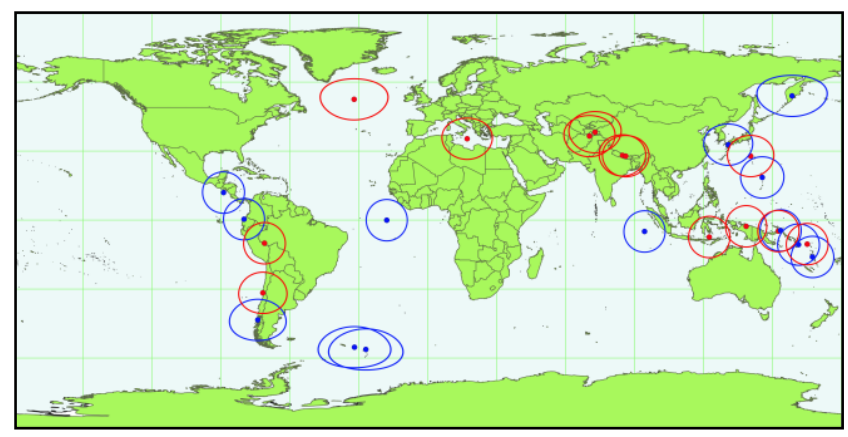

Fig. 3. Representation of the 15 Work Areas of $1000 \mathrm{Km}$ Radius in Each Seismic Event Greater than M7.0 during 2015 in Red, and during 2016 in Blue. 
TABLE II. TABLE OF SEISMIC EVENTS BETWEEN 2015-2016, WITH INTENSITIES GREATER THAN M7.0

Visualization of Data Managing obtained for the Analysis

\begin{tabular}{|l|l|l|l|l|}
\hline Earthquakes & Days & Hour & $\begin{array}{l}\text { Rectangular } \\
\text { Area Names }\end{array}$ & $\begin{array}{l}\text { Total data } \\
\text { input }\end{array}$ \\
\hline 30 & 17 & 12 & 5184 & $31^{\prime} 726,080$ \\
\hline
\end{tabular}

From these data, maps with smoothed neighborhoods were generated with a periodicity of 2 hours (Fig. 4), which are the data we use to make the qualitative comparison in the 17 days prior to each event.

In Fig. 5, we show how the vTEC variations are generated for the 04:00 UT hour, these are calculated from the normal variations of the average normal TECU for the same area and the same time.

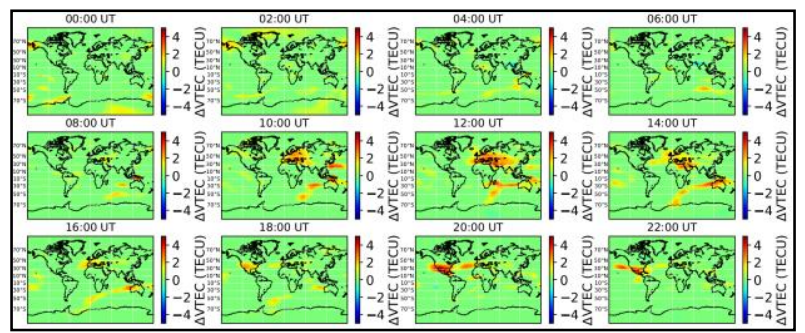

Fig. 4. Extraction of Data for Each Day of Interest, for a Period of 2 Hours.
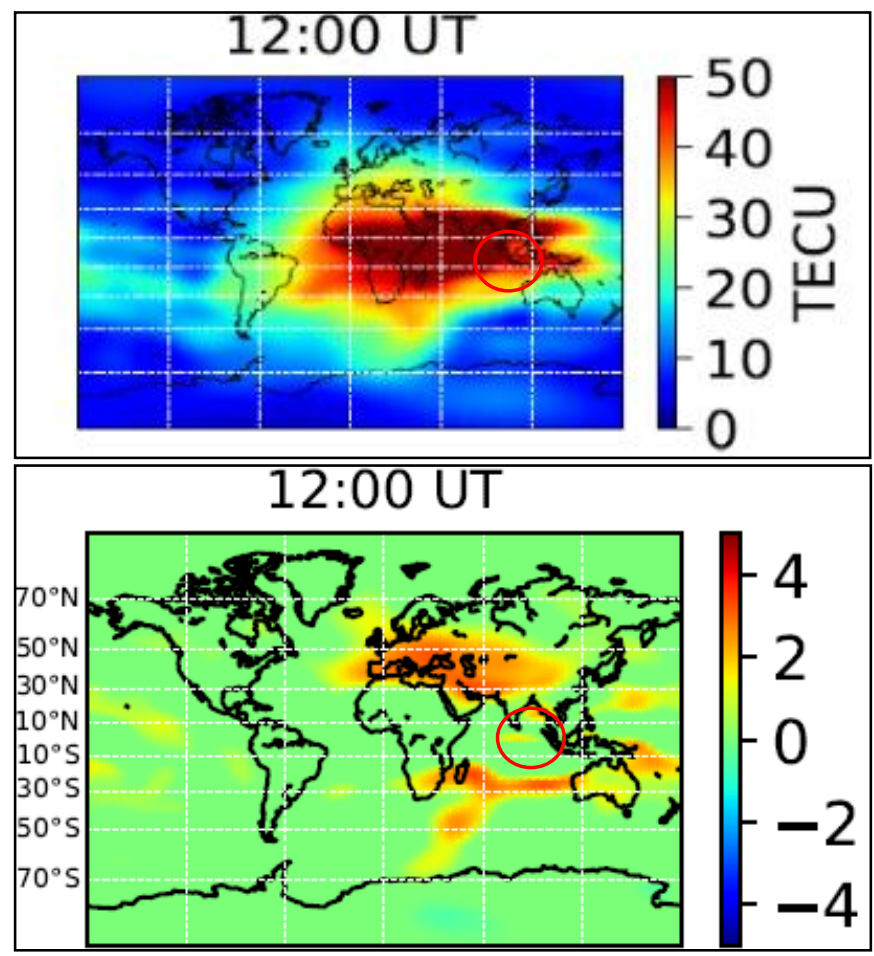

Fig. 5. Differences between the Image of the TEC Values and the Calculated Variations in a Window of 8 Days on Average, Only those that have a Variation Outside the Range for the Section and the Hour are Plotted.

The analysis performed has taken the data of the generated images as shown above and the presence of those variations on the circular area with a radius of $1000 \mathrm{~km}$. Centered on the GPS position of the seismic event analyzed. This radius has been calculated from the deduction of deformations and inclinations on the surface of the Earth as a function of the magnitude of the earthquake being prepared and the distance from the epicenter. These data are analyzed in the present study, in which we look for the association between seismic events during 2015 and 2016, and the appearance of a vTEC variation present up to 17 days before the event.

\section{METHODOLOGY}

The study carried out is an exploratory observational data model, to associate the frequency in which, given a telluric event greater than M7.0, we find evidence of a significant variation of vTEC in the ionosphere in a circular area with a radius of one kilometer from the event.

For this reason, the images generated from the CODE data, up to 17 days previously, have been analyzed. For all telluric events of 2015, and we have analyzed frequency, for days, for hours, for positive variation, and negative.

We will show below the work done for one of the events in Peru (Latitude -10.06, Longitude -71.02) on November $24^{\text {th }}$, 2015 of magnitude M7.7.

Fig. 6 shows the exact location of the seismic event on the world map.

The area of interest to analyze is a circle of radius of 1000 km (Fig. 7).

We searched each map generated every 2 hours in the period of 17 days before the event and 4 days later, the presence of significant variations in the vTEC, such as it is described in the methodology on the area of interest marked in Fig. 7. We show some examples of how these maps have been qualitatively visualized in this initial study (Fig. 8, 9, 10 and 11).

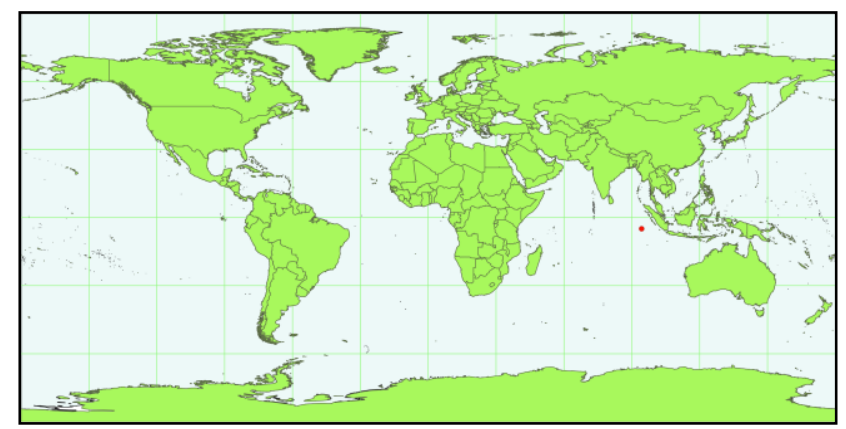

Fig. 6. Representation of the Seismic Event in Indonesia on March $2^{\text {nd }}$, 2016.

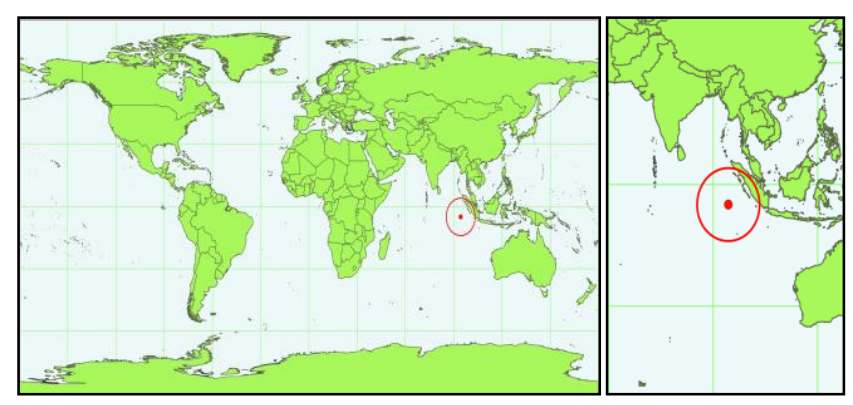

Fig. 7. Representation of the Seismic Event in Peru on March $2^{\text {nd }}, 2016$, with the Circular Area of $1000 \mathrm{~km}$. around the Point of the Earthquake. 

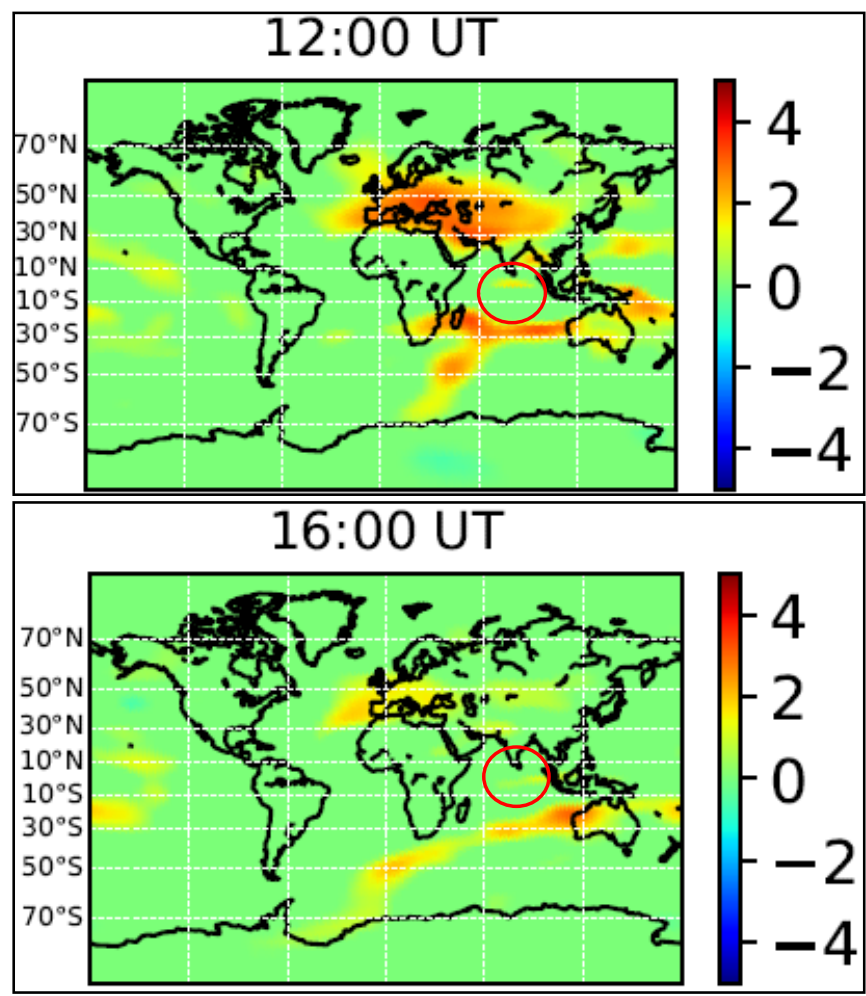

Fig. 8. Day 15 before the Event on March $2^{\text {nd }}, 2016$ (February $15^{\text {th }}, 2016$ ).
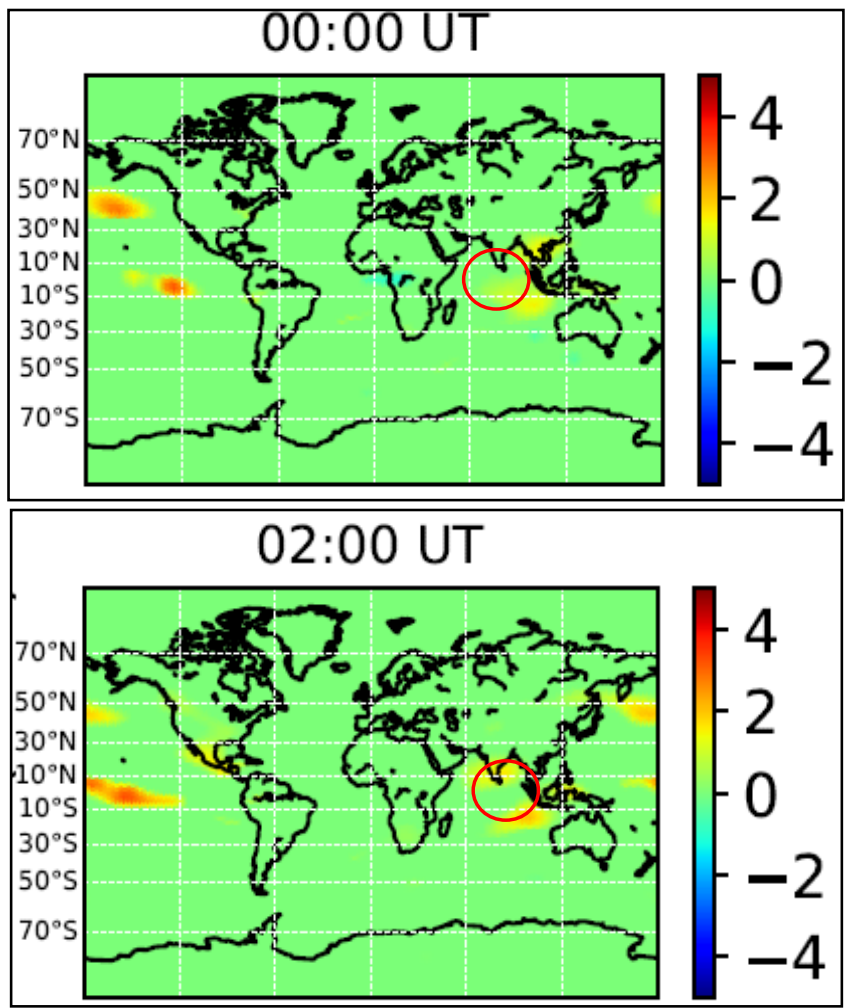

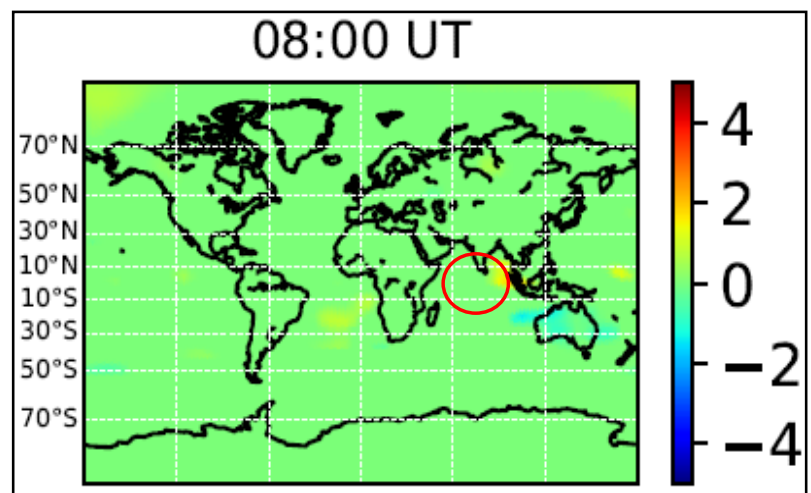

Fig. 9. Day 14 before the Event on March $2^{\text {nd }}, 2016$ (February 16 ${ }^{\text {th }}, 2016$ ).
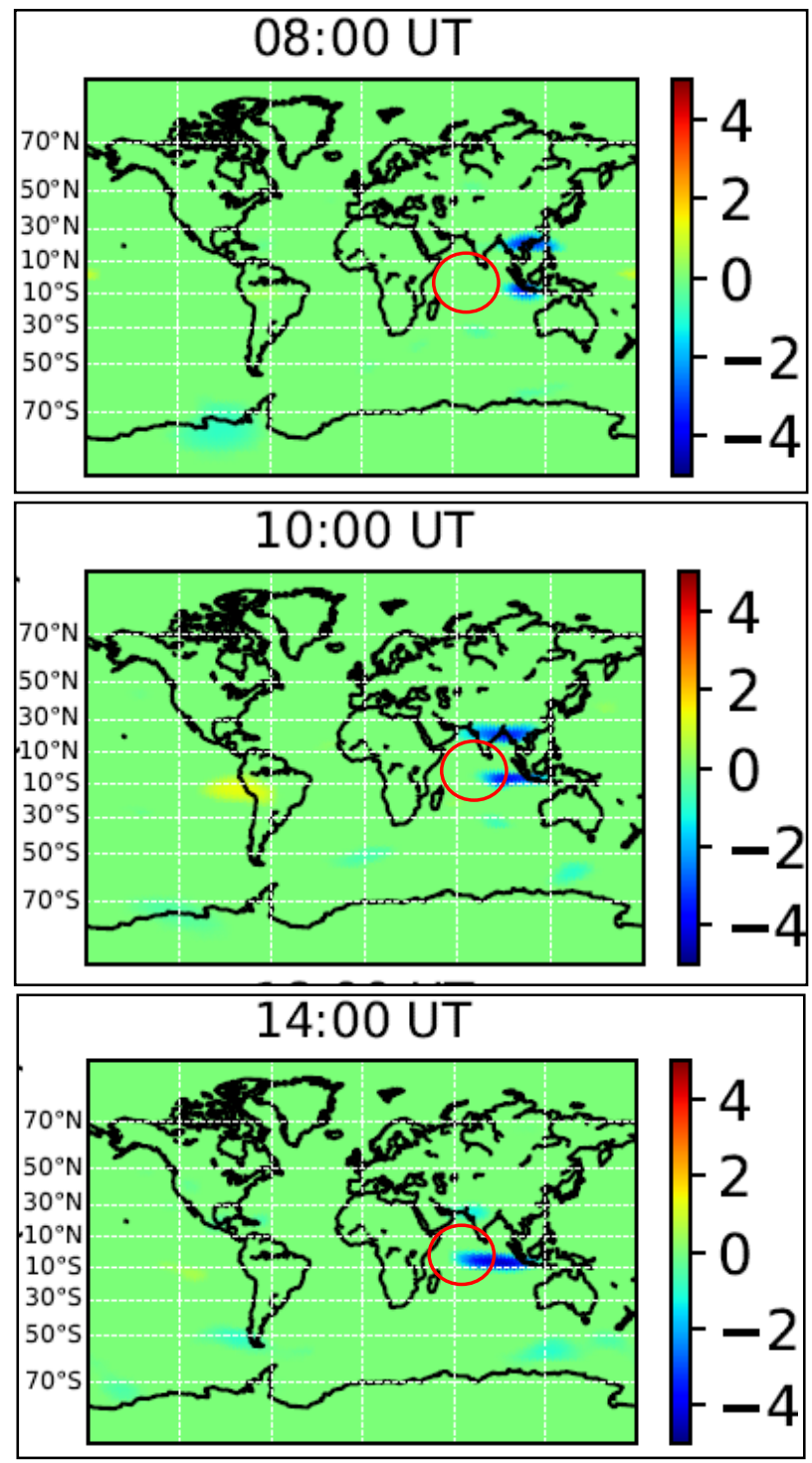

Fig. 10. Day 6 before the Event on March $2^{\text {nd }}, 2016$ (February 24 $4^{\text {th }}, 2016$ ). 


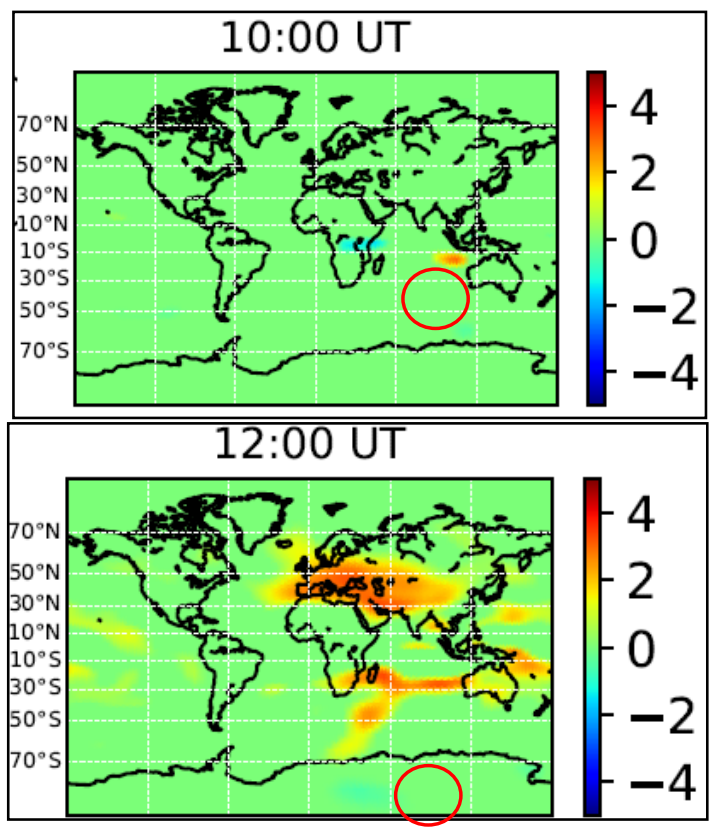

Fig. 11. Day 4 before the Event on March $2^{\text {nd }}, 2016$ (February $26^{\text {th }}, 2016$ ).
The analysis of the data for this event was carried out in which we can observe the following results. Given the event in Indonesia, a variation was observed in 12 of the 17 days analyzed previously, the presence of a significant vTEC variation, with a total of 66 hours approximately. In 34 of these hours, the variation was positive with a higher load than the expected average, and only in 32 hours was a variation less than normal considered by the statistical calculation. All these variations analyzed on the area of defined influence plotted in the monitoring of variations shown.

\section{RESULTS AND CONCLUSIONS}

The process explained for the analysis was carried out in each of the telluric events of 2015-2016. We analyzed and obtained the following table of results. Table III, where we can observe the event, the number of days, the hours and the type of variation of vTEC that were found.

The objective of this study was to observe and explore the association of a variation of vTEC before the telluric event during 2015-2016 based on qualitative analysis from the images generated by the software from INTI-Lab research team led by Dr. Carlos Sotomayor.

TABLE III. DATA ANALYSIS EVENT OF 2015-2016

\begin{tabular}{|c|c|c|c|c|c|}
\hline \multicolumn{6}{|c|}{ Register of observed variations of the telluric events 2015-2016 } \\
\hline Place & Year & $\begin{array}{l}\text { Total days with vTEC } \\
\text { variation } 17 \text { days before }\end{array}$ & $\begin{array}{l}\text { Total hours with vTEC } \\
\text { variation } 17 \text { days before }\end{array}$ & Positive variation of $v T E C$ & $\begin{array}{l}\text { Negative variation of } \\
\text { vTEC }\end{array}$ \\
\hline Dorsal Meso-Atlantic North & 2015 & 3 & 22 & 18 & 4 \\
\hline Indonesia & 2015 & 6 & 22 & 22 & 0 \\
\hline Papua Nueva Guinea & 2015 & 2 & 34 & 16 & 18 \\
\hline Nepal & 2015 & 6 & 38 & 28 & 10 \\
\hline Japan & 2015 & 4 & 24 & 24 & 0 \\
\hline Nepal & 2015 & 4 & 34 & 22 & 12 \\
\hline Dorsal Meso-Atlantic South & 2015 & 3 & 16 & 16 & 0 \\
\hline Solomon Islands & 2015 & 5 & 26 & 20 & 6 \\
\hline Indonesia & 2015 & 3 & 12 & 12 & 0 \\
\hline Chile & 2015 & 3 & 10 & 8 & 2 \\
\hline Afghanistan & 2015 & 2 & 6 & 4 & 2 \\
\hline Peru & 2015 & 7 & 28 & 26 & 2 \\
\hline Pakistan & 2015 & 2 & 6 & 6 & 0 \\
\hline Russia & 2016 & 4 & 28 & 14 & 14 \\
\hline Indonesia & 2016 & 12 & 66 & 34 & 32 \\
\hline Japan & 2016 & 12 & 48 & 40 & 8 \\
\hline Ecuador & 2016 & 12 & 32 & 26 & 6 \\
\hline Vanuatu & 2016 & 8 & 48 & 40 & 8 \\
\hline Visokoy Island & 2016 & 4 & 10 & 10 & 0 \\
\hline Northern Mariana Islands & 2016 & 7 & 22 & 20 & 2 \\
\hline New Caledonia & 2016 & 3 & 12 & 10 & 2 \\
\hline Argentina & 2016 & 1 & 2 & 0 & 2 \\
\hline $\begin{array}{l}\text { Santa Elena, Ascencion and } \\
\text { Tristan de Acuña }\end{array}$ & 2016 & 6 & 24 & 8 & 16 \\
\hline New Zealand & 2016 & 3 & 8 & 8 & 0 \\
\hline New Zealand & 2016 & 6 & 42 & 38 & 4 \\
\hline El Salvador & 2016 & 5 & 32 & 30 & 2 \\
\hline Solomon Islands & 2016 & 6 & 22 & 20 & 2 \\
\hline Papua New Guinea & 2016 & 7 & 26 & 24 & 2 \\
\hline Chile & 2016 & 4 & 14 & 14 & 0 \\
\hline
\end{tabular}


TABLE IV. DATA ANALYSIS EVENT OF 2015-2016

\begin{tabular}{|c|c|c|c|c|c|c|c|c|c|c|c|c|c|c|c|c|c|c|c|}
\hline \multicolumn{20}{|c|}{ DAYS BEFORE THE EVENT } \\
\hline Place & 0 & 1 & 2 & 3 & 4 & 5 & 6 & 7 & 8 & 9 & 10 & 11 & 12 & 13 & 14 & 15 & 16 & 17 & $T$ \\
\hline $\begin{array}{l}\text { Dorsal Meso- } \\
\text { Atlantic North }\end{array}$ & 0 & 0 & 0 & 0 & 0 & 0 & 1 & 0 & 0 & 0 & 0 & 1 & 0 & 0 & 0 & 0 & 0 & 0 & 2 \\
\hline Indonesia & 0 & 1 & 0 & 1 & 1 & 0 & 0 & 0 & 0 & 0 & 1 & 0 & 1 & 0 & 0 & 0 & 1 & 0 & 6 \\
\hline $\begin{array}{l}\text { Papua Nueva } \\
\text { Guinea }\end{array}$ & 0 & 0 & 1 & 0 & 0 & 0 & 0 & 0 & 0 & 0 & 0 & 0 & 0 & 1 & 0 & 0 & 0 & 0 & 2 \\
\hline Nepal & 1 & 1 & 1 & 0 & 0 & 0 & 0 & 0 & 0 & 0 & 0 & 0 & 0 & 0 & 1 & 1 & 0 & 0 & 5 \\
\hline Japan & 0 & 0 & 0 & 0 & 0 & 1 & 0 & 0 & 0 & 1 & 1 & 0 & 1 & 0 & 0 & 0 & 0 & 0 & 4 \\
\hline Nepal & 0 & 0 & 0 & 0 & 0 & 1 & 0 & 0 & 0 & 1 & 1 & 0 & 1 & 0 & 0 & 0 & 0 & 0 & 4 \\
\hline $\begin{array}{l}\text { Dorsal Meso- } \\
\text { Atlantic South }\end{array}$ & 0 & 1 & 1 & 1 & 0 & 0 & 0 & 0 & 0 & 0 & 0 & 0 & 0 & 0 & 0 & 0 & 0 & 0 & 3 \\
\hline Solomon Islands & 0 & 1 & 1 & 0 & 1 & 1 & 0 & 0 & 1 & 0 & 0 & 0 & 0 & 0 & 0 & 0 & 0 & 0 & 5 \\
\hline Indonesia & 0 & 0 & 0 & 0 & 0 & 0 & 0 & 0 & 0 & 0 & 1 & 1 & 0 & 0 & 0 & 1 & 0 & 0 & 3 \\
\hline Chile & 0 & 0 & 0 & 0 & 0 & 0 & 1 & 1 & 1 & 0 & 0 & 0 & 0 & 0 & 0 & 0 & 0 & 0 & 3 \\
\hline Afghanistan & 0 & 1 & 0 & 0 & 0 & 0 & 0 & 0 & 1 & 0 & 0 & 0 & 0 & 0 & 0 & 0 & 0 & 0 & 2 \\
\hline Peru & 0 & 1 & 1 & 1 & 1 & 1 & 0 & 0 & 0 & 0 & 0 & 0 & 0 & 0 & 1 & 0 & 1 & 0 & 7 \\
\hline Pakistan & 0 & 0 & 0 & 0 & 0 & 0 & 1 & 1 & 0 & 0 & 0 & 0 & 0 & 0 & 0 & 0 & 0 & 0 & 2 \\
\hline Russia & 0 & 0 & 0 & 0 & 0 & 0 & 1 & 0 & 0 & 1 & 1 & 1 & 0 & 0 & 0 & 0 & 0 & 0 & 4 \\
\hline Indonesia & 1 & 1 & 1 & 1 & 1 & 0 & 1 & 0 & 1 & 0 & 1 & 1 & 0 & 1 & 1 & 1 & 0 & 0 & 12 \\
\hline Japan & 1 & 1 & 1 & 1 & 0 & 0 & 1 & 0 & 0 & 1 & 1 & 0 & 1 & 1 & 1 & 0 & 1 & 1 & 12 \\
\hline Ecuador & 0 & 1 & 1 & 1 & 0 & 1 & 0 & 1 & 1 & 0 & 1 & 1 & 1 & 1 & 1 & 0 & 0 & 1 & 12 \\
\hline Vanuatu & 0 & 0 & 0 & 0 & 0 & 0 & 1 & 0 & 0 & 0 & 1 & 0 & 1 & 1 & 1 & 1 & 1 & 1 & 8 \\
\hline Visokoy Island & 0 & 0 & 0 & 0 & 0 & 0 & 0 & 1 & 0 & 0 & 1 & 1 & 1 & 0 & 0 & 0 & 0 & 0 & 4 \\
\hline $\begin{array}{l}\text { Northern Mariana } \\
\text { Islands }\end{array}$ & 0 & 0 & 0 & 0 & 1 & 1 & 0 & 1 & 1 & 1 & 1 & 0 & 1 & 0 & 0 & 0 & 0 & 0 & 7 \\
\hline New Caledonia & 0 & 0 & 0 & 0 & 0 & 1 & 0 & 0 & 0 & 1 & 0 & 0 & 0 & 0 & 1 & 0 & 0 & 0 & 3 \\
\hline Argentina & 0 & 0 & 0 & 0 & 0 & 0 & 0 & 0 & 0 & 0 & 0 & 0 & 0 & 0 & 0 & 0 & 0 & 1 & 1 \\
\hline $\begin{array}{l}\text { Santa Elena, } \\
\text { Ascencion and } \\
\text { Tristan de Acuña }\end{array}$ & 1 & 1 & 0 & 1 & 0 & 0 & 1 & 0 & 0 & 0 & 0 & 0 & 0 & 1 & 0 & 0 & 0 & 1 & 6 \\
\hline New Zealand & 0 & 1 & 0 & 0 & 0 & 0 & 0 & 0 & 1 & 0 & 0 & 0 & 0 & 0 & 1 & 0 & 0 & 0 & 3 \\
\hline New Zealand & 0 & 1 & 1 & 1 & 1 & 0 & 0 & 0 & 0 & 0 & 1 & 0 & 0 & 0 & 0 & 0 & 1 & 0 & 6 \\
\hline El Salvador & 0 & 0 & 0 & 0 & 0 & 0 & 0 & 0 & 0 & 1 & 0 & 1 & 1 & 1 & 1 & 0 & 0 & 0 & 5 \\
\hline Solomon Islands & 1 & 1 & 1 & 0 & 0 & 0 & 1 & 1 & 0 & 0 & 0 & 0 & 0 & 0 & 1 & 0 & 0 & 0 & 6 \\
\hline $\begin{array}{l}\text { Papua New } \\
\text { Guinea }\end{array}$ & 0 & 0 & 0 & 0 & 0 & 0 & 1 & 1 & 1 & 1 & 1 & 0 & 0 & 0 & 1 & 1 & 0 & 0 & 7 \\
\hline Chile & 0 & 0 & 0 & 0 & 1 & 0 & 0 & 1 & 0 & 0 & 0 & 0 & 0 & 0 & 0 & 1 & 1 & 0 & 4 \\
\hline
\end{tabular}

In Table IV, we can see that each event had manifestations of significant variation in $100 \%$ of the cases and the days in which it was present in a dichotomous manner.

From the table, we see that the minimum manifestation occurred in only 1 of the 17 days before the event and the maximum manifestation occurred in 12 days of the 17 days before the event. It should be noted that in the $96.55 \%$ of events previously, there is a positive variation, and that only in $68.97 \%$ of events the variation of vTEC is negative. On average in 2015-2016, the variation was maintained for the period of 5.17 days previously; this variation was presented for approximately 24.62 hours. That means the manifestation is not momentary, there is a period of time where variation is in the area of analysis selected for each event during 2015 and 2016. In Fig. 12, we can observe the frequency of events that have a manifestation of the variation of vTEC in the " $n$ " days before the earthquake.

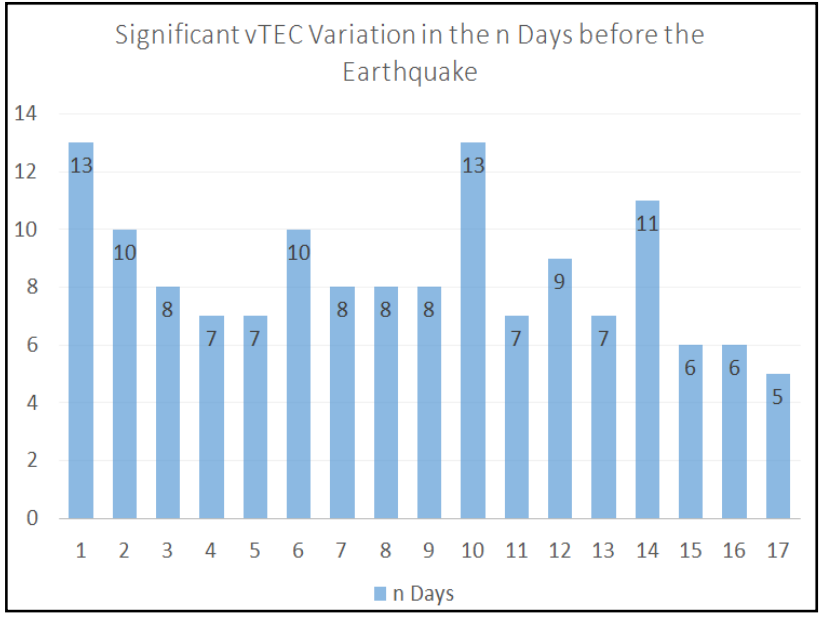

Fig. 12. Frequency of Events Days before the Earthquake. 
A vTEC variation was found in a circular area of $1000 \mathrm{~km}$ radius at least one day before the seismic event of the 20152016 data. It is also important to mention that this manifestation has not occurred once since it has been a behavior that was observed in more than 1 day before the earthquake event. We have observed that a significant variation has been found in $100 \%$ of the cases, even in the range from 3 to 17 days before the event; it is $96.55 \%$ when range is from day 5 to day 17 previous the event; and finally, if our range is restricted from day 8 to day 17 the variation is presented in $93.10 \%$ of cases. These data are necessary, in our case, because we want an algorithmic tool to model a risk and calculate with more prior days for a possible earthquake calculated from the analysis of the vTEC in the ionosphere.

The physical mechanism as to how these events happened before the earthquakes can be explained by the model of ionization of the air due to radiation from the ground $[13,14,15]$. This model estates that when tectonics plates collide with each other, besides producing earthquakes, radon is produced as a product of these collisions. This gas along with others is then released to the lower atmosphere. The presence of radon in the lower atmosphere will then provoke the ionization of the other gases presented here. However, it has been indicated [15] that other factors like air temperature or relative air humidity can also affect atmospheric ionization. Depending on the level of ionization of the atmosphere positive or negative variation of vTEC can be observed. If the air ionization produces heavy ions, then the air conductivity will decrease causing the increment of electrons in the ionosphere. This in turn will produced the positive variations of vTEC. Such mechanism is very likely to the cause of the positive variations observed before the earthquakes that happened in Indonesia, Nepal, Japan, Chile, Peru, Ecuador, New Zeland and El Salvador. On the other hand, if the level of air ionization is low, light ions will be produced. This type of ions will increase the air conductivity and therefore a decrease on is vTEC expected. This decrease of vTEC translates in to negative variations of VTEC. We suggest that the negative variations observed before the earthquakes that occurred in Papua Nueva Guinea, Nepal, Russia, Indonesia and Santa Elena, Ascencion and Tristan de Acuña, are very likely the product of the aforementioned mechanism. In order to verify this theory of the collision of tectonics plates been the cause of the variations of vTEC, studies of radon in the locations where the earthquakes happen would be beneficial [16].

It is important to mention that this study is preliminary because it has served to explore the association between telluric events and the variation of vTEC in the preliminary days during a period of 2 years. The objective of our next study will be to observe causality between a variation of vTEC and telluric events in a given area.

We want to thank the Universidad de Ciencias y Humanidades (UCH) for the support in carrying out the study and the funding in this initial stage for the proof of concept.

\section{REFERENCES}

[1] N. N. Ambraseys, "Value of Historical Records of Earthquakes," Nature, vol. 232, no. 5310, pp. 375-379, Aug. 1971.

[2] B. Gutenberg and C. F. Richter, "Magnitude and energy of earthquakes," Ann. Geophys., pp. 7-12, 2010.

[3] B. Gutenberg and C. F. Richter, "Magnitude and Energy of Earthquakes," Nature, vol. 176, no. 4486, p. 795, Oct. 1955.

[4] [4] S. Orjuela, D. A. Molina, and F. Y. Zapata, "en la ionosfera durante un terremoto," p. 6, 2015.

[5] "Catalogo Sismico De La Zona Comprendida Entre Los Meridianos 5o E. Y 20o W. De Greenwich Y Los ParalelOS 45o Y 25o N. Tomo II | José Galbis Rodriguez | Comprar libro mkt0003098317.” [Accessed: 25-Aug2018].

[6] I. P. Dobrovolsky, S. I. Zubkov, and V. I. Miachkin, "Estimation of the size of earthquake preparation zones," Pure Appl. Geophys., vol. 117, no. 5, pp. 1025-1044, Sep. 1979.

[7] M. T. C. Pérez and V. M. M. Castro, "Climatología, Cambios Climáticos Y Atmósfera,” vol. 30, no. 1, p. 10, 2010.

[8] Z. Fuying, W. Yun, Z. Yiyan, and L. Jian, "A statistical investigation of pre-earthquake ionospheric TEC anomalies," Geod. Geodyn., vol. 2, no. 1, pp. 61-65, Feb. 2011.

[9] M. H. Sarachaga and F. Sánchez-Dulcet, "Efectos De La Actividad Sísmica En La Ionosfera; Características Y Posibles Aplicaciones," p. 13.

[10] M. Wyss, "Evaluation of Proposed Earthquake Precursors," Eos Trans. Am. Geophys. Union, vol. 72, no. 38, pp. 411-411, Sep. 1991.

[11] F. Zhu, Y. Wu, J. Lin, and Y. Zhou, "Temporal and spatial characteristics of VTEC anomalies before Wenchuan Ms8.0 earthquake," Geod. Geodyn., vol. 1, no. 1, pp. 23-28, Jan. 2010.

[12] "IRIS Earthquake Browser." [Online]. Available: http://ds.iris.edu/ieb/index.html?format=text\&nodata=404\&starttime $=197$ 0-01-01\&endtime $=2025-01-01 \&$ minmag $=0 \&$ maxmag $=10 \&$ mindepth $=0 \&$ maxdepth $=900 \&$ orderby $=$ time-desc $\&$ limit $=1000 \&$ maxlat $=89.21 \&$ minlat $=-89.21 \&$ maxlon $=180.00 \&$ minlon $=-180.00 \& \mathrm{zm}=1 \& \mathrm{mt}=$ ter [Accessed: 25-Aug-2018].

[13] C. Sotomayor-Beltran, "Ionospheric anomalies preceding the low-latitude earthquake that occurred on April 16, 2016 in Ecuador," Journal of Atmospheric and Solar-Terrestrial Physics, vol. 182, pp. 61-66, 2019

[14] S. Pulinets, "Low-latitude atmosphere-ionosphere effects initiated by strong earthquakes preparation process," Int. J. Geophysics, vol. 2012, pp.1-14, 2012

[15] V.M Sorokin, "Plasma and electromagnetic effects in the ionosphererelated to the dynamics of charged aerosols in the lower atmosphere," Russian Journal of Physical Chemestry B, vol 1, pp.138170,2007

[16] S. Pulinets, "Radon and ionosphere monitoring as a mean for strong earthquakes forecast," Nuovo Cimento, p. 621-626, 1999. 